\title{
Should We Screen for Hearing Loss in the Older Adult?
}

\author{
Katbryn Rooney, MD, University of New Mexico, Albuquerque, New Mexico \\ Ann Fam Med 2020;18(6):iii. https://doi.org/10.1370/afm.2614.
}

The Annals of Family Medicine encourages readers to develop a learning community to improve health care and health through enhanced primary care. Participate by conducting a journal club. We encourage diverse participants to think critically about important issues affecting primary care and act on those discussions. ${ }^{1}$

\section{HOW IT WORKS}

In each issue, the Annals selects an article and provides discussion tips and questions. Post a summary of your conversation in our online discussion. (Open the article, click on the eLetters tab, and submit a comment.) Discussion questions and information are online at: https://www.AnnFamMed.org/content/AJC.

\section{CURRENT SELECTION}

\section{Article for Discussion}

Zazove P, Plegue MA, McKee MM, et al. Effective hearing loss screening in primary care: the early auditory referral-primary care study. Ann Fam Med. 2020;18(6):520-527.

\section{Discussion Tips}

Hearing loss is a common condition affecting older adults aged 55 years and older. The prevalence of this condition doubles with every 10 -year increase in age. Individuals who experience hearing loss suffer from impaired communication, leading to higher rates of comorbidities and impaired quality of life. ${ }^{2}$ The US Preventive Services Task Force does not make a recommendation regarding routine auditory screening in asymptomatic adults, stating that current evidence is insufficient to assess the benefits and harms of screening (Grade: I). ${ }^{3}$ The authors describe the Early Auditory Referral-Primary Care (EAR-PC) study, which assesses the use of an electronic alert system to prompt clinicians to ask eligible patients about difficulty with hearing. The study examines the utility of this alert in identifying patients with possible hearing loss and referral of these patients to audiologists. ${ }^{4}$

\section{Discussion Questions}

- What question is asked by this study and why does it matter?

- What is a multiple baseline design?

- What is a Best Practice Alert (BPA)? Does the electronic health record used by your practice utilize BPAs for patient care?

- Describe the grade definitions of the US Preventive Services Task Force Recommendations. How do you evaluate and incorporate recommendations with grade I into your practice?

- To what degree can the findings of this study be accounted for by:

o Characteristics of the health systems where the study was conducted?

o How participants were selected to participate in and consented for the study?

o The use of the general medicine "control" group?

- How comparable is the study sample to patients in your practice?

- What are the main study findings?

- How might this study change your practice? Would you consider implementing a BPA for hearing loss? For other health care screenings?

- How does this study advance beyond previous research and clinical practice on this topic?

-What researchable questions remain?

\section{References}

1. Stange KC, Miller WL, McLellan LA, et al. Annals Journal Club: It's time to get RADICAL. Ann Fam Med. 2006:4(3):196-197. https:// AnnFamMed.org/cgi/content/full/4/3/196.

2. Cunningham LL, Tucci DL. Hearing loss in adults. N Engl J Med. 2017;377(25):2465-2473. 10.1056/NEJMra1616601.

3. US Preventive Services Task Force. Hearing loss in older adults: screening. US Preventive Services Task Force. https://www.uspreventiveservicestaskforce.org/uspstf/draft-recommendation/hearing-lossin-older-adults-screening-2021. Published Aug 2012. Accessed Sep 27, 2020.

4. Zazove P, Plegue MA, McKee MM, et al. Effective hearing loss screening in primary care: the early auditory referral-primary care study. Ann Fam Med. 2020;18(6):520-527. 